\title{
PENGARUH KREDIBILITAS ENDORSER LOKAL TERHADAP IKLAN KOSMETIK DAN MINAT BELI KONSUMEN
}

\section{THE INFLUENCE OF THE LOCAL ENDORSERS' CREDIBILITY ON COSMETIC ADVERTISEMENTS AND CONSUMER BUYING INTEREST}

\author{
Fadli ${ }^{1}{ }^{\star}$, Alvi Rahmania $\left.{ }^{2}\right)$ \\ 1,2Akademi Farmasi Yarsi Pontianak \\ Jalan Panglima Aim No. 2 - Pontianak \\ `e-mail: fadliapoteker@yahoo.com
}

Diterima: 16 Mei 2021, Revisi 28 Juni 2021, Diterbitkan: 30 Juni 2021

\begin{abstract}
The credibility of local endorsers is one of the factors to rely on the truth of the message that the advertisers convey, whose ad targets are local people. Cosmetics advertisements are a means of communication for products delivered through social media to attract the consumer buying interest. The purpose of this study was to determine whether the local endorsers' credibility on cosmetic advertisement affected the consumers' buying interest. This research was a survey. The sample comprised 92 respondents, Year-11 students of SMA Negeri 1 Sungai Raya Kepulauan, Bengkayang Regency, West Kalimantan, selected using purposive sampling technique. The data were collected with a google form delivered through online access, and they were analyzed quantitatively. The results showed that the significance value of the local endorser credibility variable $(X)$ on the cosmetic advertising variable (Y1) in the coefficients table was $0.000<0.05$ and the count value was $8.768>$ 1.990 , and the influence of the local endorser credibility variable on the cosmetics advertising variable was 46.0 . \%, categorized sufficient, while the result of the local endorser credibility variable test $(X)$ on the purchase intention variable (Y2) was significant $0.000<0.05$ and count of $4.170>1.990$, and the influence of the variable was $16.2 \%$, categorized low but definite. The conclusion of this study is that there is an influence of local endorsers' credibility on cosmetic advertising and consumer buying interest.
\end{abstract}

Keyword: Credibility Of Local Endorsers, Cosmetic Advertising and Buying Interest.

\begin{abstract}
ABSTRAK
Kredibilitas endorser lokal adalah salah satu faktor yang dapat dipertimbangkan untuk mempercayai kebenaran isi pesan yang disampaikan oleh pengiklan, dimana target iklannya adalah orang lokal. Iklan kosmetik merupakan media untuk menyampaikan produk melalui media sosial untuk menarik minat beli konsumen. Tujuan dari penelitian ini adalah untuk mengetahui apakah ada pengaruh kredibilitas endorser lokal terhadap iklan kosmetik dan minat beli konsumen. Metode penelitian ini adalah metode survey, yang datanya diperoleh dengan teknik observasi dan alatnya dikirimkan secara daring dalam bentuk google form. Data penelitian dianalisis secara kuantitatif. Sampel penelitian berjumlah 92 responden yang ditentukan dengan teknik purposive sampling. Mereka adalah pelajar remaja kelas 11 SMA Negeri 1 Sungai Raya Kepulauan, Kabupaten Bengkayang, Kalimantan Barat. Hasil penelitian menunjukkan bahwa nilai signifikansi variabel kredibilitas endorser lokal $(X)$ terhadap variabel iklan kosmetik $\left(Y_{1}\right)$ pada tabel coefficients sebesar $0,000<0,05$ dan nilai thitung sebesar 8,768 $>1,990$ serta pengaruh variabel kredibilitas endorser lokal terhadap variabel iklan kosmetik sebesar $46,0 \%$ dan dikategorikan cukup berpengaruh. Hasil uji variabel kredibilitas endorser lokal $(X)$ terhadap variabel minat beli $\left(\mathrm{Y}_{2}\right)$ adalah signifikan sebesar $0,000<0,05$ dan thitung sebesar 4,170 $>1,990$ serta pengaruh dari variabelnya sebesar $16,2 \%$ dan dikategorikan berpengaruh rendah tapi pasti. Kesimpulan dari penelitian ini adalah terdapat pengaruh kredibilitas endorser lokal terhadap iklan kosmetik dan minat beli konsumen.
\end{abstract}

Kata Kunci: Kredibilitas Endorser Lokal, Iklan Kosmetik dan Minat Beli 


\section{PENDAHULUAN}

Kosmetik saat ini telah menjadi kebutuhan manusia yang tidak bisa dianggap sebelah mata. Baik wanita maupun pria setiap hari tidak lepas dari kosmetik, dalam berbagai bentuk seperti lotion untuk kulit, powder, sabun, deodorant, dan lain-lain. Sekarang, semakin terasa akan kebutuhan kosmetik yang beraneka ragam, warna dan keunikan kemasan serta keunggulan dalam fungsi bagi konsumen. Realita tersebut memberikan peluang bagi industri kosmetik untuk semakin mengembangkan teknologi baik dari aspek fungsi kosmetik maupun kepraktisan dalam penggunannya. Produk kosmetik kecantikan sudah begitu marak di pasaran dan semakin banyak persaingan. Oleh karenanya, menjadi hal yang penting bagi suatu perusahaan untuk menginformasikan produknya ke pasaran, dengan kreatif, menarik dan mudah diingat untuk menumbuhkan minat konsumen.

Iklan merupakan sarana
komunikasi tentang produk yang disampaikan melalui berbagai media dengan biaya pemrakarsa agar masyarakat tertarik untuk menyetujui dan mengikuti. Efektifitas iklan bergantung pada struktur dan isi pesan (Putra, Said, and Hasan, 2017). Iklan yang digunakan sebagai media promosi terbukti memiliki peran yang penting dalam memperkenalkan suatu merek (Gunawan, 2014).

Secara umum kredibilitas endorser bisa diartikan sebagai suatu karakteristik positif komunikator yang berpengaruh terhadap penerimaan suatu pesan oleh receiver (Stafford, Marla, Stafford, Thomas, and Day, 2002). Kredibilitas endorser menjadi salah satu faktor yang dipertimbangkan oleh responden untuk mempercayai kebenaran isi pesan yang disampaikan oleh pengiklanan. Endorser berperan sangat penting dalam membantu menciptakan awareness (kesadaran). Selain itu, iklan yang menggunakan selebriti terkenal akan terlihat lebih menarik bagi konsumen.

Penelitian ini bertujuan untuk melihat pengaruh penggunaan endorser lokal dalam suatu iklan dan faktor-faktor yang mempengaruhi konsumen dalam proses pengambilan keputusan terhadap produk yang memanfaatkan jasa endorser lokal. Endorser lokal merujuk kepada orang yang berasal dari lokal yang memiliki peran untuk mendukung iklan.

Remaja merupakan salah satu sasaran konsumen yang dapat dituju oleh pemasar untuk memasarkan produknya. Remaja adalah kelompok masyarakat dalam suatu rentang usia yang sudah bukan anakanak lagi, namun belum bisa dibilang dewasa. Secara psikologis, kaum remaja terbilang belum matang; oleh karena itu, karakter mereka yang menonjol adalah dinamis, sering berubah-ubah, ikut-ikutan tren, ingin sesuatu yang baru, dan mudah sekali terpengaruhi. Pada saat ini, remaja lebih banyak mendapat pengaruh dari teman dan figur yang mereka anggap mewakili diri mereka yang dapat mereka serap dari berbagai macam informasi yang mereka lihat (Sarwono, 2007).

Hasil observasi terhadap beberapa siswa SMA Negeri 1 Sungai Raya Kepulauan menunjukkan bahwa banyak di antara mereka menjadi tertarik membeli produk kosmetik yang iklannya mereka lihat diendorse oleh endorser local di sosial. Mereka jarang membeli kosmetik secara online; mereka membelinya langsung di toko terdekat. Merujuk kepada observasi tersebut, peneliti ingin melakukan penelitian terkait kredibilitas endorser, iklan kosmetik dan minat beli pada remaja SMA.

Menurut Randi dan Heryanto (2016) minat dalam pembelian menciptakan suatu motivasi yang terus terekam dalam benak konsumen dan menjadi suatu keinginan yang sangat kuat yang pada akhirnya ketika seorang konsumen harus memenuhi kebutuhannya, mereka akan mengaktualisasikan apa yang ada di dalam benaknya. Tingkah laku dalam minat konsumen ditunjukkan dengan sikap atau keinginan seseorang sebelum melakukan suatu tindakan pembelian. Konsumen yang mulai merasa terstimulasi oleh keinginan suatu produk atau jasa bisa disebut minat beli. Minat beli merupakan faktor penting yang mendorong dan mempengaruhi seseorang dalam memutuskan pembelian 
terhadap suatu produk. Menurut Setiadi (2003), minat beli dibentuk dari sikap konsumen terhadap produk yang terdiri dari kepercayaan terhadap merek dan evaluasi merek, sehingga dari dua tahap tersebut muncul minat untuk membeli. Tujuannya adalah untuk mengetahui apakah ada pengaruh kredibilitas endorser lokal terhadap iklan kosmetik dan minat beli.

Penelitian ini dilakukan sebagai langkah awal untuk melihat serta mengungkapkan pengaruh kreadibilitas endorser. Dengan demikian, penelitian ini diberi judul "Pengaruh Kredibilitas Endorser Lokal Terhadap Iklan Kosmetik dan Minat Beli Konsumen".

\section{METODE}

Desain penelitian ini adalah analisis kuantitatif dengan cara melakukan observasi terlebih dahulu dan pemberian kuesioner melalui google form yang dilakukan untuk mengumpulkan seluruh data.

Populasi merupakan seluruh subjek atau objek dengan karakteristik tertentu yang akan diteliti (Notoatmodjo, 2010). Populasi penelitian ini adalah pelajar Kelas 11 di SMA Negeri 1 Sungai Raya Kepulauan Angkatan Tahun 2019/2020, berusia 15-20 tahun, dan berjumlah 120 orang Jumlah sampel penelitian ini dihitung dengan menggunakan rumus Slovin sebagai berikut:

Keterangan:

$$
n=\frac{N}{\left(1+N e^{2}\right)}
$$

$\mathrm{n} \quad=$ Jumlah sampel yang diperlukan

$\mathrm{N} \quad=$ Jumlah populasi e $\quad=$ Tingkat kesalahan sampel

(sampling error), biasanya 5\%

$$
\begin{gathered}
n=\frac{N}{1+N(e)^{2}} \\
n=\frac{120}{1+120(0,05)^{2}}
\end{gathered}
$$

$n=92,30 \rightarrow$ dibulatkan 92

Berdasarkan ketentuan di atas, maka sampel penelitian ini berjumlah 92 responden. Menurut Sugiyono (2017), ukuran sampel yang layak dalam penelitian adalah antara 30 sampai dengan 500 .

Menurut Sugiyono (2017) sampling adalah teknik pengambilan sampel. Teknik sampling yang digunakan dalam penelitian ini adalah purposive sampling termasuk dalam jenis kelompok teknik nonprobability sampling yaitu, teknik pengambilan sampel yang tidak memberi peluang atau kesempatan sama bagi setiap unsur (anggota) populasi untuk dipilih menjadi sampel. Karena pengambilan anggota sampel berdasarkan pada suatu pertimbangan tertentu, sampel penelitian harus memiliki kriteria sebagai berikut :

1. Kriteria Inklusi

a. Responden yang berusia 15-20 tahun.

b. Bersedia untuk menjadi responden.

c. Memiliki akses internet.

d. Memiliki smartphone atau laptop.

2. Kriteria Eksklusi

a. Responden menolak berpartisipasi.

b. Tidak adanya akses internet.

c. Tidak adanya smartphone atau laptop.

\section{Definisi Operasional Variabel}

Tabel 1. Definisi Operasional Variabel

\begin{tabular}{cll}
\hline \multicolumn{1}{c}{ Variabel } & \multicolumn{1}{c}{ Definisi Operasional } & \multicolumn{1}{c}{ Indikator } \\
\hline endorser lokal & $\begin{array}{l}\text { pendukung dalam iklan yang } \\
\text { berasal dari lokal (indonesia) }\end{array}$ & $\begin{array}{l}\text { memiliki followers yang banyak di } \\
\text { sosial media }\end{array}$ \\
\hline $\begin{array}{cll}\text { kredibilitas } \\
\text { endorser }\end{array}$ & $\begin{array}{l}\text { seseorang yang dapat } \\
\text { dipercaya menjadi daya tarik } \\
\text { yang serta mempunyai } \\
\text { keahlian. }\end{array}$ & $\begin{array}{l}\text { daya tarik, keahlian, dan } \\
\text { kepercayaan }\end{array}$ \\
\hline iklan kosmetik & $\begin{array}{l}\text { pesan yang menawarkan suatu } \\
\text { produk. }\end{array}$ & - perhatian (attetion) \\
& & - minat (interest) \\
& & - keinginan (desire) \\
& & rasa percaya (conviction) \\
\hline
\end{tabular}


- tindakan (action)

$\begin{array}{lll}\text { minat beli } & \text { suatu sikap sehingga } & \text { - tertarik untuk mencari informasi } \\ \text { menimbulkan suatu ketertarikan } & \text { tentang produk } \\ \text { dan dapat mempertimbangkan } & - \text { mempertimbangkan untuk } \\ \text { dalam mengambil keputusan. } & \text { mencoba } \\ & - \text { tertarik untuk mencoba } \\ & - \text { keinginan untuk mengetahui } \\ & \text { produk } \\ & - \text { keinginan untuk memiliki produk }\end{array}$

Teknik pengumpulan data penelitian ini menggunakan kuesioner yang disebarkan dalam bentuk google form secara online kepada responden yaitu, pelajar SMA Negeri 1 Sungai Raya Kepulauan Angkatan Tahun 2019/2020 dengan menggunakan 27 item pernyataan. Menurut Arikunto (2013) kuesioner adalah sejumlah pertanyaan tertulis untuk memperoleh informasi dari responden dalam arti laporan tentang pribadinya, atau hal - hal yang ia ketahui.

Kuesioner yang disebarkan memiliki alternatif jawaban sangat tidak setuju (STS), tidak setuju (TS), ragu-ragu (RG), setuju (S), sangat setuju (SS). Kuesioner pada penelitian ini sudah dilakukan uji validitas. Uji ini digunakan untuk mengukur valid tidaknya suatu kuesioner. Jawaban soal dari masingmasing soal akan diberikan pembobotan atau nilai. Untuk skor nilai jawaban diberi seperti sangat tidak setuju bernilai 1, tidak setuju bernilai 2 , ragu-ragu bernilai 3 , setuju bernilai 4, dan sangat setuju bernilai 5 (Sugiyono, 2017).

Penelitian ini menggunakan uji validitas korelasi pearson product moment (Notoatmodjo, 2010).

Tabel 2. Hasil Uji Validitas Kuesioner

\begin{tabular}{cccccc}
\hline Variabel & $\begin{array}{c}\text { No. } \\
\text { Item }\end{array}$ & rhitung & $\begin{array}{c}\text { rtabel } \\
\mathbf{5 \%} \\
\mathbf{( 3 0 )}\end{array}$ & Sig. & Kriteria \\
\hline Kredibilitas & P1 & 0,754 & 0,361 & 0,000 & Valid \\
Endorser & P2 & 0,846 & 0,361 & 0,000 & Valid \\
Lokal (X) & P3 & 0,718 & 0,361 & 0,000 & Valid \\
& P4 & 0,539 & 0,361 & 0,002 & Valid \\
& P5 & 0,634 & 0,361 & 0,000 & Valid \\
& P6 & 0,806 & 0,361 & 0,000 & Valid \\
& P7 & 0,861 & 0,361 & 0,000 & Valid \\
& P8 & 0,778 & 0,361 & 0,000 & Valid \\
\hline Iklan & P9 & 0,733 & 0,361 & 0,000 & Valid \\
Kosmetik & P10 & 0,850 & 0,361 & 0,000 & Valid \\
$\left(\right.$ Y $\left._{1}\right)$ & P11 & 0,739 & 0,361 & 0,000 & Valid \\
& P12 & 0,789 & 0,361 & 0,000 & Valid
\end{tabular}

\begin{tabular}{cccccc}
\hline & P13 & 0,768 & 0,361 & 0,000 & Valid \\
& P14 & 0,816 & 0,361 & 0,000 & Valid \\
& P15 & 0,772 & 0,361 & 0,000 & Valid \\
& P16 & 0,769 & 0,361 & 0,000 & Valid \\
& P17 & 0,861 & 0,361 & 0,000 & Valid \\
& P18 & 0,884 & 0,361 & 0,000 & Valid \\
& P19 & 0,796 & 0,361 & 0,000 & Valid \\
& P20 & 0,600 & 0,361 & 0,000 & Valid \\
Minat Beli & P21 & 0,742 & 0,361 & 0,000 & Valid \\
$\left(Y_{2}\right)$ & P22 & 0,835 & 0,361 & 0,000 & Valid \\
& P23 & 0,567 & 0,361 & 0,001 & Valid \\
& P24 & 0,529 & 0,361 & 0,003 & Valid \\
& P25 & 0,773 & 0,361 & 0,000 & Valid \\
& P26 & 0,772 & 0,361 & 0,000 & Valid \\
& P27 & 0,634 & 0,361 & 0,000 & Valid \\
\multicolumn{2}{c}{ Sumber : Data yang diolah, 2021 } & & &
\end{tabular}

Seperti terlihat pada Tabel 2, semua butir pernyataan dalam kuesioner adalah valid. Hal ini terbukti bahwa item pernyataan yang dinyatakan valid yaitu rhitung $>$ rabel atau dengan nilai signifikansi $<0,05$ yang artinya 27 butir (item) pernyataan tersebut dapat dipergunakan untuk melakukan analisis selanjutnya.

Tabel 3. Hasil Uji Reliabilitas dengan SPSS Variabel Cronbach's N of Items Alpha

\begin{tabular}{lcr}
\hline Kredibilitas & 0,887 & 8 \\
Endorser Lokal $(\mathrm{X})$ & & \\
Iklan Kosmetik $\left(\mathrm{Y}_{1}\right)$ & 0,939 & 12 \\
$\quad$ Minat Beli $\left(\mathrm{Y}_{2}\right)$ & 0,818 & 7 \\
\hline Sumber : Data yang diolah, 2021 & &
\end{tabular}

Tabel 3 menunjukkan bahwa Cronbach's Alpha variabel (X) 0,887>0,06 dan variabel $\left(Y_{1}\right) \quad 0,939>0,06$ serta variabel $\left(Y_{2}\right)$ 0,818>0,06. Butir kuesioner dikatakan reliable jika memberikan nilai Cronbach's Alpha >0,06 (Ghozali, 2011). Berdasarkan hasil data tersebut, diperoleh nilai Cronbach's Alpha $>0,06$ sehingga kuesioner dapat dikatakan reliable atau kuesioner layak dan dilanjutkan untuk penelitian selanjutnya. 
Kemudian dilanjutkan dengan analisis univariat untuk mengetahui umur dan jenis kelamin responden, yang datanya diperoleh dari masing-masing variabel.

Hipotesis penelitian ini diuji dengan uji T dengan bantuan aplikasi software SPSS.25 dengan taraf signifikansi $5 \%$ atau 0,05. Berdasarkan perbandingan nilai $t$ hitung dengan t tabel:

a. Jika nilai t hitung $>t$ tabel, maka hipotesis diterima.

b. Jika nilai t hitung $<\mathrm{t}$ tabel, maka hipotesis ditolak.

Untuk melihat pengaruh hubungan antar variabel, maka data dianalisis dengan menggunakan regresi linier berganda, dimana dilakukan uji normalitas terlebih dahulu dengan menggunakan uji Kolmogorov Smirnov dikarenakan jumlah responden penelitian $\geq 30$ (di atas sama dengan 30) memiliki nilai (Sig $\geq 0,05)$. Jika data terdistribusi normal, maka dapat dilanjutkan menggunakan regresi linier berganda.

a. Jika nilai signifikansi $<0,05$, maka variabel bebas $(X)$ berpengaruh terhadap variabel terikat $(\mathrm{Y})$.

b. Jika nilai signifikansi $>0,05$, maka variabel bebas $(X)$ tidak berpengaruh terhadap variabel terikat $(\mathrm{Y})$.

Dengan model persamaan sebagai berikut:

a. Persamaan I

Keterangan:

$$
Y_{1}=a+b X+e
$$

$\mathrm{Y}_{1}=$ Iklan kosmetik (variabel terikat)

$\mathrm{X}=$ Kredibilitas endorser lokal (variabel bebas)

$\mathrm{a}=$ Konstanta

$\mathrm{b}=$ Koefisien regresi

$\mathrm{e}=$ standar error

b. Persamaan II

Keterangan:

$$
\mathrm{Y}_{2}=\mathrm{a}+\mathrm{bX}+\mathrm{e}
$$

$\mathrm{Y}_{2}=$ Minat beli (variabel terikat)

$\mathrm{X}=$ Kredibilitas endorser lokal (variabel bebas)

$\mathrm{a}=$ Konstanta

$\mathrm{b}=$ Koefisien regresi

e $=$ standar error

Koefisien korelasi adalah bilangan

yang menyatakan kekuatan hubungan antara dua variabel atau lebih atau juga

dapat menentukan arah dari kedua variabel. Nilai $R$ akan berkisar antara $0-1$, semakin mendekati 1, hubungan antara variabel independen secara bersama-sama dengan variabel dependen semakin kuat.

Tabel 4. Pedoman Interpretasi Koefisien Korelasi

Interval Koefisien

$0,00-0,199$

$0,40-0,599$

$0,60-0,799$

$0,80-1000$
$0,20-0,399$

Tingkat Hubungan

Sangat Rendah

Rendah

Sedang

Kuat

Sangat kuat

Sumber: Metode Penelitian Kuantitatif (Siregar, 2013)

Koefisien determinasi $\left(R^{2}\right)$ bertujuan untuk mengukur seberapa jauh kemampuan model dalam menerapkan variasi variabel dependen. Nilai koefisien determinasi adalah antara nol dan satu. Nilai $\left(R^{2}\right)$ yang kecil berarti kemampuan variabel independen dalam menjelaskan variasi variabel dependen amat terbatas. Nilai yang mendekati satu berarti variabel independen memberikan hampir semua informasi yang dibutuhkan untuk memprediksi variasi variabel dependen (Ghozali, 2011).

Koefisien determinasi dapat dicari dengan menggunakan rumus sebagai berikut:

$$
K D=(r)^{2} \times 100 \%
$$

Keterangan:

$$
\begin{array}{ll}
\mathrm{Kd} & =\text { Koefisien determinasi } \\
\mathrm{r}^{2} & =\text { Kuadrat dan koefisien }
\end{array}
$$

Tabel 5. Pedoman Interpretasi Koefisien

Determinasi

\begin{tabular}{rc}
\hline \multicolumn{1}{c}{ Pernyataan } & Keterangan \\
$>4 \%$ & Pengaruh Rendah Sekali \\
$5 \%-16 \%$ & Pengaruh Rendah Tapi Pasti \\
$17 \%-49 \%$ & Pengaruh Cukup Berarti \\
$50 \%-80 \%$ & Pengaruh Tinggi atau Kuat \\
$>80 \%$ & Pengaruh Tinggi Sekali \\
\hline Sumber : (Supranto, 2010) &
\end{tabular}

\section{HASIL DAN PEMBAHASAN}

1. Analisis Univariat

Tabel 6. Distribusi Frekuensi Respoden

Berdasarkan Umur

\begin{tabular}{ccrrr}
\hline N & Mean & Median & $\begin{array}{c}\text { Standar } \\
\text { Deviation }\end{array}$ & Min-Max \\
\hline 92 & 16,86 & 17,00 & 1,085 & $15-20$ \\
\hline Sumber : & Data Primer, 2021 & & \\
\end{tabular}

Tabel 6 menunjukkan bahwa distribusi responden berdasarkan umur memiliki ratarata 16,86 tahun dengan umur terendah 15 tahun dan umur tertinggi 20 tahun. 
Tabel 7. Distribusi Frekuensi Responden Berdasarkan Umur

\begin{tabular}{lrr}
\hline Umur & Frekuensi & Persentase \\
\hline 15 tahun & 3 & $3,3 \%$ \\
16 tahun & 36 & $39,1 \%$ \\
17 tahun & 36 & $39,1 \%$ \\
18 tahun & 9 & $9,8 \%$ \\
19 tahun & 4 & $4,3 \%$ \\
20 tahun & 4 & $4,3 \%$ \\
\hline Total & 92 & $100 \%$
\end{tabular}

Sumber : Data Primer, 2021

Data di atas menunjukkan bahwa jumlah responden yang berumur 15 tahun hanya berjumlah 3 responden $(3,3 \%)$, sedangkan responden terbanyak berada pada rentang umur 16 tahun sebanyak 36 responden $(39,1 \%)$, dan berumur 17 tahun sebanyak 36 responden $(39,1 \%)$.

Tabel 8. Distribusi Frekuensi Responden Berdasarkan Jenis Kelamin

\begin{tabular}{crr}
\hline Jenis Kelamin & Frekuensi & Persentase \\
\hline Laki-laki & 30 & $32,6 \%$ \\
Perempuan & 62 & $67,4 \%$ \\
\hline Total & 92 & $100 \%$
\end{tabular}

Sumber : Data Primer, 2021

Pada Tabel 8 terlihat, responden yang terbanyak adalah yang berjenis kelamin perempuan yaitu, sebanyak 62 responden $(67,4 \%)$ dan laki-laki yaitu sebanyak 30 responden $(32,6 \%)$.

\section{Analisis Bivariat}

Tabel 9. Hasil Uji Normalitas

\begin{tabular}{|c|c|c|c|c|}
\hline \multicolumn{5}{|c|}{ One-Sample Kolmogorov-Smirnov Test } \\
\hline & & $\begin{array}{l}\text { Kredibilitas } \\
\text { Endorser } \\
\text { Lokal }\end{array}$ & $\begin{array}{l}\text { Iklan } \\
\text { Kosmetik }\end{array}$ & $\begin{array}{l}\text { Minat } \\
\text { Beli }\end{array}$ \\
\hline \multicolumn{2}{|l|}{$\mathrm{N}$} & 92 & 92 & 92 \\
\hline Normal & Mean & 28,88 & 39,66 & 27,75 \\
\hline Parameters ${ }^{a, b}$ & Std. Deviation & 4,283 & 6,663 & 2,839 \\
\hline \multirow{3}{*}{$\begin{array}{l}\text { Most Extreme } \\
\text { Differences }\end{array}$} & Absolute & 081 & ,085 & 084 \\
\hline & Positive & 071 & 067 & 084 \\
\hline & Negative &,- 081 &,- 085 &,- 070 \\
\hline \multicolumn{2}{|l|}{ Test Statistic } & 081 & ,085 & ,084 \\
\hline \multicolumn{2}{|c|}{$\begin{array}{l}\text { Asymp. Sig. (2-tailed) } \\
\text { a. Test distribution is Normal. }\end{array}$} &, $171^{\mathrm{c}}$ & $100^{\mathrm{c}}$ & $106^{c}$ \\
\hline
\end{tabular}

Sumber : Data yang diolah, 2021

Terlihat pada Tabel 9, pada variabel kredibilitas endorser lokal didapatkan nilai Asymp. Sig. (2-tailed) 0,171 > 0,05 yang bermakna bahwa data tersebut berdistribusi normal. Pada variabel iklan kosmetik didapatkan nilai Asymp. Sig. (2-tailed)
0,100>0,05 yang bermakna bahwa data tersebut berdistribusi normal dan pada minat beli didapatkan nilai Asymp. Sig. (2-tailed) $0,106>0,05$ yang memiliki arti bahwa data tersebut juga berdistribusi normal.

Tabel 10. Hasil Uji T

\begin{tabular}{|c|c|c|c|c|c|c|}
\hline \multicolumn{7}{|c|}{ Coefficients $^{a}$} \\
\hline \multirow[b]{2}{*}{ Model } & & $\begin{array}{r}\text { Unstar } \\
\text { Coef }\end{array}$ & $\begin{array}{l}\text { dized } \\
\text { ents }\end{array}$ & $\begin{array}{l}\text { Standardized } \\
\text { Coefficients }\end{array}$ & \multirow[t]{2}{*}{$\mathrm{t}$} & \multirow[t]{2}{*}{ Sig. } \\
\hline & & $B$ & Std. Error & Beta & & \\
\hline \multirow[t]{2}{*}{1} & (Constant) & 9,181 & 3,517 & & 2,611 & ,011 \\
\hline & $\begin{array}{l}\text { Kredibilitas Endorser } \\
\text { Lokal }\end{array}$ & 1,055 &, 120 & ,678 & 8,762 &, 000 \\
\hline
\end{tabular}

a. Dependent Variable: Iklan Kosmetik

Sumber : Data yang diolah, 2021

Merujuk kepada Tabel 10 pada kredibilitas endorser lokal didapatkan nilai signifikansi sebesar $0,000<$ probabilitas 0,05 dengan nilai $t$ hitung sebesar 8,762>1,990, maka dapat diartikan bahwa hipotesis diterima karena variabel kredibilitas endorser lokal (X) berpengaruh secara parsial terhadap iklan kosmetik (Y1). 
Tabel 11. Hasil Uji T

\begin{tabular}{|c|c|c|c|c|c|c|}
\hline \multirow[b]{2}{*}{ Model } & & $\begin{array}{r}\text { Coe } \\
\text { Unstan } \\
\text { Coef }\end{array}$ & $\begin{array}{l}\text { ients }{ }^{a} \\
\text { dized } \\
\text { ents }\end{array}$ & \multirow{2}{*}{$\begin{array}{c}\text { Standardized } \\
\text { Coefficients } \\
\text { Beta }\end{array}$} & \multirow[t]{2}{*}{$\mathrm{t}$} & \multirow[t]{2}{*}{ Sig. } \\
\hline & & B & Std. Error & & & \\
\hline \multirow[t]{2}{*}{1} & (Constant) & 20,049 & 1,867 & & 10,739 & ,000 \\
\hline & $\begin{array}{l}\text { Kredibilitas Endorser } \\
\text { Lokal }\end{array}$ & ,267 & ,064 & ,402 & 4,170 & 000 \\
\hline
\end{tabular}

Sumber : Data yang diolah, 2021

Pada Tabel 11, hasil uji $T$ menununjukkan kredibilitas endorser lokal berada pada nilai signifikansi sebesar 0,000 $<$ probabilitas 0,05 dengan nilai t hitung sebesar 4,170>1,990. Ini bermakna bahwa hipotesis diterima karena variabel kredibilitas endorser lokal (X) berpengaruh secara parsial terhadap minat beli (Y2).

Tabel 12. Hasil Uji Koefisien Korelasi (R) dan Uji Koefisien Determinasi $\left(\mathbf{R}^{2}\right)$

\begin{tabular}{|c|c|c|c|c|}
\hline \multicolumn{5}{|c|}{ Model Summary } \\
\hline Model & $\mathrm{R}$ & $\mathrm{R}$ & Adjusted & Std. \\
\hline & & $\begin{array}{l}\text { Squar } \\
\mathrm{e}\end{array}$ & R Square & $\begin{array}{l}\text { Error of } \\
\text { the } \\
\text { Estimate }\end{array}$ \\
\hline 1 & $678^{a}$ & 460 & ,454 & 4,922 \\
\hline
\end{tabular}

a. Predictors: (Constant), Kredibilitas Endorser Lokal b. Dependent Variable: Iklan Kosmetik

Sumber : Data yang diolah, 2021

Berdasarkan Tabel 12, besarnya nilai korelasi atau hubungan $(R)$ adalah 0,678. Hal ini berarti terdapat hubungan kuat antara variabel kredibilitas endorser lokal dengan variabel iklan kosmetik. Karena output tersebut diperoleh koefisien determinasi ( $R$ Square) sebesar 0,460 hampir mendekati 1, maka dapat diartikan bahwa pengaruh kredibilitas endorser lokal (X) terhadap variabel iklan kosmetik $\left(\mathrm{Y}_{1}\right)$ adalah sebesar $46,0 \%$ atau dikategorikan pengaruh cukup. Untuk mencari koefisien determinasi digunakan rumus:

$$
\begin{aligned}
K D & =(r)^{2} \times 100 \% \\
& =(0,678)^{2} \times 100 \% \\
& =46,0 \%
\end{aligned}
$$

\begin{tabular}{|c|c|c|c|c|}
\hline \multicolumn{5}{|c|}{ Model Summaryb } \\
\hline Model & $\mathrm{R}$ & $\begin{array}{l}\text { R } \\
\text { Square }\end{array}$ & $\begin{array}{l}\text { Adjusted } \\
\text { R Square }\end{array}$ & $\begin{array}{l}\text { Std. } \\
\text { Error of } \\
\text { the } \\
\text { Estimate }\end{array}$ \\
\hline 1 &, $402^{\mathrm{a}}$ &, 162 & , 153 & 2,613 \\
\hline $\begin{array}{l}\text { a. Predi } \\
\text { b. Depe }\end{array}$ & $\begin{array}{l}\text { S: }(\mathrm{C} \\
\text { nt } \mathrm{Va}\end{array}$ & $\begin{array}{l}\text { tant), Kr } \\
\text { ble: Mine }\end{array}$ & $\begin{array}{l}\text { libilitas End } \\
\text { Beli }\end{array}$ & er Lokal \\
\hline
\end{tabular}

Tabel 13. Hasil Uji Koefisien Korelasi (R) dan Uji Koefisien Determinasi $\left(\mathbf{R}^{2}\right)$

Berdasarkan Tabel 13, besarnya nilai korelasi atau hubungan (R) sebesar 0,402. Hasil ini menunjukkan adanya hubungan sedang antara variabel kredibilitas endorser lokal dengan variabel minat beli. Output tersebut diperoleh koefisien determinasi ( $R$ Square) sebesar 0,162 atau hampir mendekati 1. Hal ini diartikan bahwa pengaruh kredibilitas endorser lokal (X) terhadap variabel minat beli $\left(\mathrm{Y}_{2}\right)$ adalah sebesar $16,2 \%$ atau dikategorikan pengaruh rendah tapi pasti. Untuk mencari koefisien determinasi dengan menggunakan rumus:

\begin{tabular}{|c|c|c|c|c|c|c|}
\hline \multicolumn{7}{|c|}{ Coefficients $^{a}$} \\
\hline \multirow[b]{2}{*}{ Model } & & $\begin{array}{r}\text { Unstar } \\
\text { Coee }\end{array}$ & $\begin{array}{l}\text { rdized } \\
\text { ents }\end{array}$ & $\begin{array}{c}\text { Standardized } \\
\text { Coefficients }\end{array}$ & \multirow{2}{*}{$\mathrm{t}$} & \multirow{2}{*}{ Sig. } \\
\hline & & $\mathrm{B}$ & Std. Error & Beta & & \\
\hline 1 & (Constant) & 9,181 & 3,517 & & 2,611 &, 011 \\
\hline & $\begin{array}{l}\text { Kredibilitas Endorser } \\
\text { Lokal }\end{array}$ & 1,055 &, 120 & ,678 & 8,762 &, 000 \\
\hline
\end{tabular}

$$
\begin{aligned}
K D & =(r)^{2} \times 100 \% \\
& =(0,162)^{2} \times 100 \% \\
& =16,2 \%
\end{aligned}
$$

Tabel 14. Uji Regresi Linier Berganda 
Berdasarkan output SPSS 25 statistic Tabel 14, maka persamaan regresi linier berganda dapat dirumuskan sebagai berikut:

$$
Y_{1}=9,181+1,055 X
$$

Dari hasil uji tersebut, maka dapat dijelaskan bahwa:

1) Konstanta persamaan di atas sebesar 9,181 angka tersebut menunjukkan bahwa jika X (kredibilitas endorser lokal) konstan (tidak berubah), maka iklan kosmetik sebesar 9,181.

2) $X \quad$ (kredibilitas endorser lokal) menunjukkan nilai koefisien sebesar
1,055. Hal ini berarti bahwa variabel kredibilitas endorser lokal mempengaruhi iklan kosmetik sebesar 1,055 ini menunjukkan bahwa setiap kenaikan kredibilitas endorser lokal sebesar satuan, maka akan meningkatkan iklan kosmetik sebesar 1,055 .

3) Berdasarkan tabel coefficients, nilai signifikansi sebesar $0,000<0,05$, yang artinya variabel kredibilitas endorser lokal $(X)$ berpengaruh signifikan terhadap variabel iklan kosmetik $\left(\mathrm{Y}_{1}\right)$

Tabel 15. Uji Regresi Linier Berganda

\begin{tabular}{|c|c|c|c|c|c|c|}
\hline \multirow[b]{2}{*}{ Model } & & $\begin{array}{r}\text { Coe } \\
\text { Unstan } \\
\text { Coef }\end{array}$ & $\begin{array}{l}\text { ients } \\
\text { rdized } \\
\text { ents }\end{array}$ & \multirow{2}{*}{$\begin{array}{c}\text { Standardized } \\
\text { Coefficients } \\
\text { Beta }\end{array}$} & \multirow[t]{2}{*}{$\mathrm{t}$} & \multirow[t]{2}{*}{ Sig. } \\
\hline & & $B$ & Std. Error & & & \\
\hline \multirow[t]{2}{*}{1} & (Constant) & 20,049 & 1,867 & & 10,739 &, 000 \\
\hline & $\begin{array}{l}\text { Kredibilitas Endorser } \\
\text { Lokal }\end{array}$ & ,267 & ,064 & ,402 & 4,170 &, 000 \\
\hline
\end{tabular}

a. Dependent Variable: Minat Beli

Sumber : Output SPSS yang diolah, 2021

Berdasarkan output SPSS 25 statistic tabel di atas, persamaan regresi linier berganda dapat dirumuskan sebagai berikut:

$$
Y_{2}=20,049+0,267 X
$$

Dari hasil uji tersebut maka dapat dijelaskan bahwa:

1) Konstanta persamaan di atas sebesar 20,049 angka tersebut menunjukkan bahwa jika X (kredibilitas endorser lokal) konstan (tidak berubah), maka minat beli sebesar 20,049.

2) $X \quad$ (kredibilitas endorser lokal) menunjukkan nilai koefisien sebesar 0,267 . Hal ini berarti bahwa variabel kredibilitas endorser lokal mempengaruhi minat beli sebesar 0,267 ini menunjukkan bahwa setiap kenaikan kredibilitas endorser lokal sebesar satuan, maka akan meningkatkan minat beli sebesar 0,267.

3) Berdasarkan tabel coefficients, nilai signifikansi sebesar 0,000 0,05 artinya variabel kredibilitas endorser lokal (X) berpengaruh signifikan terhadap variabel minat beli $\left(\mathrm{Y}_{2}\right)$.

Berikut beberapa gambar grafik dari uji regresi linier berganda, dimana bentuk grafik histogram memberikan pola. Jika tidak melenceng ke kiri dan ke kanan, maka variabel terdistribusi normal. Sebaliknya, jika bentuk grafik melenceng ke kiri atau kanan, maka variabel tidak terdistribusi normal. Grafik histogram dapat dilihat di bawah ini:

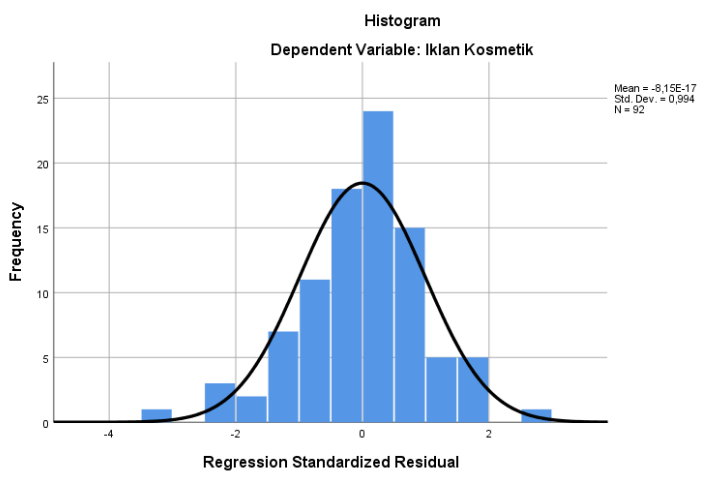

Gambar 1. Grafik Histogram Regresi Variabel Iklan Kosmetik

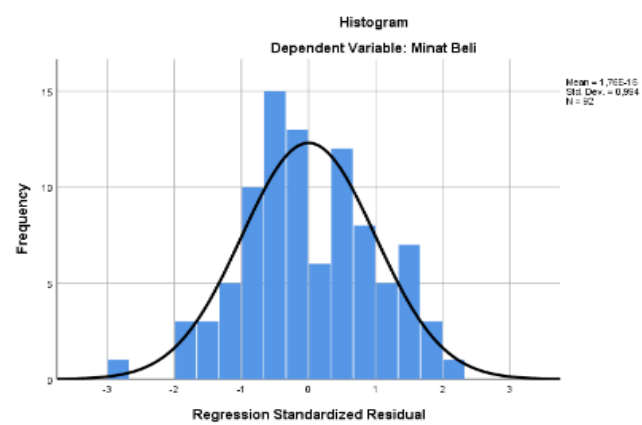

Gambar 2. Grafik Histogram Regresi Variabel Minat Beli

36 Jurnal Borneo Akcaya 
Terlihat pada Gambar 1 dan Gambar 2 data terdistribusi normal yang garisnya membentuk lengkungan dan terlihat sempurna dengan kaki simetris tidak menceng ke kanan atau ke kiri. Artinya grafik tersebut menunjukkan bahwa model regresi memenuhi asumsi normalitas.

Selanjutnya pada gambar normal $p$ plot jika terlihat titik-titik masih menyebar di sekitar garis diagonal, maka data berdistribusi normal. Sebaliknya jika tidak menyebar di sekitar garis diagonal, maka data tidak berdistribusi normal. Gambar grafik normal p-plot dapat dilihat di bawah ini:

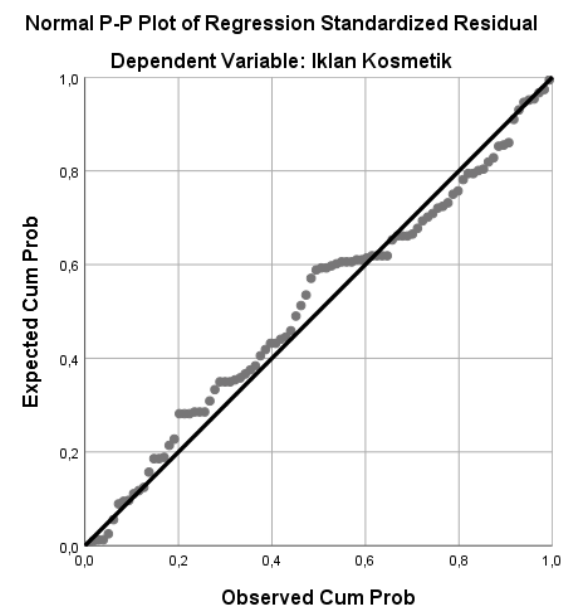

Gambar 3. Grafik Normal P-Plot Regresi Variabel Iklan Kosmetik

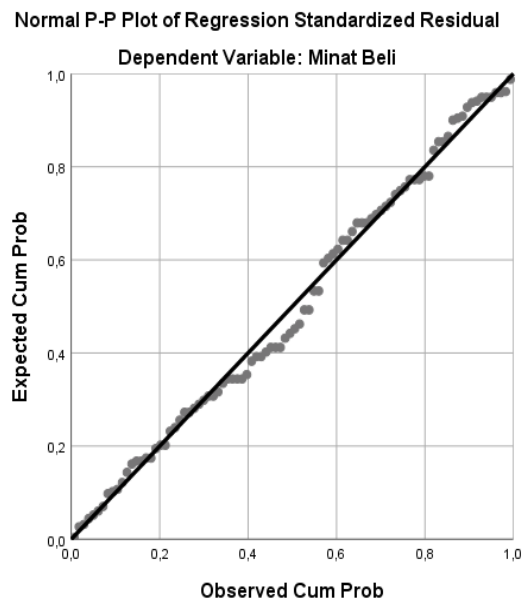

Gambar 4. Grafik Normal P-Plot Regresi Variabel Minat Beli

Dapat dilihat pada Gambar 3 grafik normal p-plot regresi variabel iklan kosmetik dan gambar 4 grafik normal $p$-plot variabel minat beli yaitu, titik-titik mengikuti dan mendekati garis diagonalnya sehingga model regresi memenuhi asumsi normalitas.
Untuk nilai residual dalam regresi linier sederhana dalam penelitian dapat terpenuhi.

Hasil penelitian ini sejalan dengan teori yang dikemukakan oleh Kinnear, Thomas, dan Taylor (2003), yang berbunyi bahwa minat beli merupakan bagian dari komponen perilaku konsumen dalam sikap mengkonsumsi dan kecenderung konsumen untuk bertindak sebelum akhirnya benarbenar melaksanakan keputusan pembelian. Iklan kosmetik bisa digunakan untuk mendapatkan atau mencari informasi mengenai pentingnya informasi dari kosmetik melalui media seperti media sosial. Selain itu, kredibilitas endorser lokal mempunyai pengaruh terhadap iklan kosmetik dan minat beli.

\section{KESIMPULAN}

Hasil penelitian yang dilakukan pada pengaruh kredibilitas endorser lokal terhadap iklan kosmetik dan minat beli konsumen menunjukkan bahwa kredibilitas endorser lokal berpengaruh terhadap iklan kosmetik dengan nilai signifikansi sebesar $0,000<0,05$ dan pengaruh interprestasi dari koefisien determinasi (R Square) sebesar $46,0 \%$ dikategorikan cukup. Kredibilitas endorser lokal berpengaruh terhadap minat beli dengan nilai signifikansi sebesar $0,000<0,05$ dan pengaruh interprestasi dari koefisien determinasi (R Square) sebesar $16,2 \%$ dikategorikan pengaruh rendah tapi pasti. Hal tersebut membuktikan adanya pengaruh kredibilitas endorser lokal terhadap iklan kosmetik dan minat beli konsumen.

\section{REKOMENDASI}

Diharapkan untuk kredibilitas endorser lokal semakin ditingkatkan sehingga minat beli konsumen juga akan semakin meningkat.

\section{UCAPAN TERIMAKASIH}

Penulis mengucapkan terima kasih kepada bapak Fadli., S.Farm., Apt. MM 
selaku dosen pembimbing yang telah memberi arahan dalam karya tulis ilmiah ini. Ucapan terima kasih juga disampaikan kepada semua pihak yang telah berperan dalam penelitian.

\section{DAFTAR PUSTAKA}

Arikunto, Suharsimi. 2013. Prosedur Penelitian Suatu Pendekatan Praktik. Jakarta: PT. Rineka Cipta.

Ghozali, Imam. 2011. Aplikasi Analisis Multivariate Dengan Program SPSS. Semarang: Badan Penerbit Universitas Diponegoro.

Gunawan, Fitri Anggraini dan Diah Dharmayanti. 2014. "Analisis Pengaruh Iklan Televisi Dan Endorser Terhadap Purchase Intention Pond's Men Dengan Brand Awareness Sebagai Variabel Intervening." Jurnal Manajemen Pemasaran Petra 2:1-14.

Kinnear, Thomas C, dan Taylor, James R. 2003. Riset Pemasaran, (Terjemahan Oleh Thamrin) Edisi Ketiga. Jakarta: Erlangga.

Notoatmodjo, S. 2010. Metodologi Penelitian Kesehatan. Jakarta: Rineka Cipta.

Putra, Aditya Halim Perdana Kusuma, Syahnur Said, and Sabri Hasan. 2017. "Pengaruh Karakteristik Toko Dan Produk Bagi Konsumen Di Indonesia Terhadap Pembelian Impulsif." Jurnal Manajemen Dan Kewirausahaan 5(2):8-19. doi: 10.26905/jmdk.v5i2.1640.

Randi. Heryanto, Meyzi. 2016. "Pengaruh Citra Merek Terhadap Minat Beli Pada Makanan Fast Food Ayam Goreng (Studi Pada Konsumenn Texas Chicken Pekanbaru)." Jurnal Online Mahasiswa Fakultas IImu Sosial Dan IImu Politik Universitas Riau 3:1-9.

Sarwono, Dr. Sarlito Wirawan. 2007. Psikolog Remaja. Jakarta: PT. Raja Grafindo Persada.

Setiadi, Nugroho. J. 2003. Perilaku 38 Jurnal Borneo Akcaya
Konsumen. Jakarta: Kencana.

Siregar, Syofian. 2013. Metode Penelitian Kuantitatif. Jakarta: PT Fajar Interpratama Mandiri.

Stafford, Marla R., Stafford, Thomas F., and Day, Ellen. 2002. "A Contingency Approach: The Effects of Spokesperson Type and Service Type on Service Advertising Perceptions." Journal of Advertising 31:17-34.

Sugiyono. 2017. Metode Penelitian Kuantitatif, Kualitatif Dan R\&D. Bandung: Alfabeta.

Supranto, J. 2010. Statistika. Jakarta: Erlangga. 